\title{
Reference range of random urinary calcium creatinine ratio in North Indian children and adolescents
}

Raman Kumar Marwaha, DNB ${ }^{1,{ }^{*}}$, Mahendra Kumar Garg, DM ${ }^{2, *}$, Navin Dang, MD ${ }^{3}$, Ambrish Mithal, $\mathrm{DM}^{4}$, Archna Narang, MD, Aditi Chadha, BHMS ${ }^{5}$, Nandita Gupta, $\mathrm{PhD}^{6}$, Manchanda Raj Kumar, MD ${ }^{7}$

'Department of Endocrinology and Thyroid Research Centre, INMAS, DRDO, Delhi, India

2Department of Medicine \& Endocrinology, All India Institute of Medical Sciences, Jodhpur, India

3Dang Laboratory, New Delhi, India

${ }^{4}$ Department of Endocrinology, Medanta Hospital, Medicity, Gurugram, India

${ }^{5}$ Department of Medicine, Dr B R Sur Homeopathic Medical College, New Delhi, India

${ }^{6}$ Department of Endocrinology, All India Institute of Medical Sciences, New Delhi, India

${ }^{7}$ Central Council of Homeopathic Research, New Delhi, India

Received: 6 July, 2018

Revised: 1 October, 2018

Accepted: 26 November, 2018

Address for correspondence: Raman Kumar Marwaha, DNB

Endocrine \& Thyroid Research Centre, Institute of Nuclear Medicine \& Allied Sciences, New Delhi, India

Tel: +91-9810296820

Fax: +91-11-26523477

E-mail: marwaha_ramank@hotmail. com

https://orcid.org/0000-0001-70038766

*These authors contributed equally to this study as co-first authors.

This is an Open Access article distributed under the terms of the Creative Commons Attribution Non-Commercial License (http:/) creativecommons.org/licenses/by-nc/4.0) which permits unrestricted non-commercial use, distribution, and reproduction in any medium, provided the original work is properly cited.
Purpose: Urinary calcium creatinine ratio $(\mathrm{UCaCrR})$ is a reliable indicator for monitoring hypercalciuria following vitamin D supplementation. However, the reference range varies from region to region. Previous studies did not take vitamin $\mathrm{D}$ and parathyroid hormone status into account while evaluating UCaCrR. Hence, we undertook this study to establish the 95th percentile of UCaCrR as an indicator of hypercalciuria in North Indian children and adolescents.

Methods: Four hundred seventy-three participants (boys 62.2\%, girls 37.8\%) with adequate dietary calcium intake, normal serum levels of 25-hydroxy-vitamin $D$ ( $>20$ $\mathrm{ng} / \mathrm{mL}$ ), and without secondary hyperparathyroidism following supplementation were selected for evaluation of UCaCrR.

Results: The mean age and body mass index of subjects were $11.2 \pm 2.6$ years and $18.0 \pm 3.6 \mathrm{~kg} / \mathrm{m}^{2}$, respectively. The 95th percentile of UCaCrR in the study population was 0.126 . The mean, median, and 95 th percentile of $\mathrm{UCaCrR}$ was significantly higher in prepubertal children (age $\leq 10$ years) $(0.0586 \pm 0.0374$, median $=0.0548$, 95 th percentile $=0.136)$ compared to those $>10$ years old $(0.0503 \pm 0.0363$, median $=0.0407$, 95th percentile $=0.123, P=0.02$ ). No significant difference in $\mathrm{UCaCrR}$ was observed between genders and different weight categories.

Conclusion: UCaCrR of 0.13 defines the cutoff value for hypercalciuria in North Indian children and adolescents with adequate dietary intake of calcium and sufficient serum vitamin D levels.

Keywords: Urinary calcium creatinine ratio, Children and adolescents, Weight category

\section{Introduction}

Urinary calcium excretion is used to evaluate various clinical conditions, such as idiopathic hypercalciuria, hyperparathyroidism, hypoparathyroidism, vitamin D intoxication, vitamin D supplementation, and calcium supplementation. ${ }^{1,2)}$ Calcium excretion depends on age, race, dietary habits, vitamin D status, renal function, and various genetic factors. ${ }^{3-10)}$ Normal calcium excretion and urinary calcium creatinine ratio (UCaCrR) cutoff values to define hypercalciuria vary in different age groups and by region. Hypercalciuria has been defined as daily urinary excretion of more than $4 \mathrm{mg}$ calcium $/ \mathrm{kg}$ body weight if a child is over 2 years old. ${ }^{11)}$ However, this definition assumes that obese children will have higher calcium excretion compared to lean children. The most accepted method of evaluating normal calcium excretion is by collecting urine for 24 hours. Urinary calcium excretion of $<200 \mathrm{mg}$ calcium/ $\mathrm{L}$ is considered normal. ${ }^{1,3)}$ However, 24-hour urine collection in children and adolescents is cumbersome and inadequate ${ }^{12,13)}$ compared to estimating by spot $\mathrm{UCaCrR}$, which is easier and more practical. Hypercalciuria is defined as UCaCrR values above the 95 th percentile. ${ }^{1,3)}$ 
Several studies have shown good correlation between UCaCrR and 24-hour urinary calcium excretion, ${ }^{12-15)}$ but some have also reported poor correlation. ${ }^{16-19)} \mathrm{UCaCrR}$ requires a reference range for different races and geographic regions. ${ }^{1,3)}$ Reference ranges for various regions and ethnic backgrounds are available in the literature, ${ }^{4-10,17-27)}$ but data from India is sparse. ${ }^{28,29)}$ In addition, none of these published studies have accounted for the dietary intake of calcium and serum 25-hydroxy-vitamin D (25OHD) levels, which likely affect UCaCrR.

Calcium homeostasis depends on calcium absorption and excretion. Calcium absorption is dependent on calcium intake and vitamin D status. Vitamin D supplementation is known to increase UCaCrR in vitamin D deficient children and adolescents. ${ }^{30,31)}$ However, UCaCrR is not affected in vitamin D sufficient children and adolescents. ${ }^{32,33)}$ Hence, vitamin D status is an important determinant of UCaCrR. If calcium absorption is inadequate, serum parathyroid hormone (PTH) rises and calcium homeostasis is maintained by altered bone resorption and renal calcium excretion. Most studies reported in the literature have not taken these factors into account to calculate UCaCrR reference ranges. It is important to select a population with normal calcium intake, vitamin D sufficiency, and normal serum PTH concentration to establish a normal reference range of UCaCrR. Hence, we undertook this study (1) to create reference ranges of $\mathrm{UCaCrR}$ by age in healthy vitamin D sufficient children with adequate calcium intake, and (2) to define cutoff limits of UCaCrR for defining hypercalciuria.

\section{Materials and methods}

\section{Subjects}

This study was performed in 4 schools in Delhi (Latitude North $28.38^{\circ}$, East $77.12^{\circ}$ ), India (representing mid socioeconomic strata) with consent from school authorities, parents/ guardians, and verbal assent from children. Parents were asked to sign the consent form after they were provided with details of the study in a patient information sheet and allowed to ask the first author any questions. All children and adolescents with vitamin D deficiency were supplemented with vitamin D for 6 months as part of a trial (Fig. 1). ${ }^{31)}$ There were 702 children and adolescents who achieved serum $25 \mathrm{OHD}$ value of $\geq 50 \mathrm{nmol} / \mathrm{L}$ with serum PTH of $<65 \mathrm{ng} / \mathrm{L}$. Of these, 229 had dietary calcium intake less than the recommended daily allowance (RDA) as per the Indian Council of Medical Research (ICMR)34); these subjects were excluded from the study. The remaining 473 subjects with adequate daily dietary intake of calcium were included in the analysis (Fig. 1). Subjects were advised not to change their lifestyle with regard to sun exposure and dietary habits during the study period. Children and adolescents who were either on drugs affecting urinary calcium excretion, such as calcium, vitamin D, glucocorticoids, anti-tubercular drugs, or antiepileptic drugs, or suffering from any systemic illness were excluded from the study.
Dietary calcium assessment was carried out using a 24hour recall method with one working day and one holiday wherein all foods consumed in the last 24 hours were evaluated with household measures and ingredients. Total daily calcium intake was estimated for both days using a computer based comprehensive diet assessment known as the DietSoft software, version:1.1.7 (developed by Invincible IDeAS [www.invincibleideas.com] based on the book Nutritive Value of Indian Foods by C Gopalan, BV RamaSastri, and SC Balasubrsmanian, National Institute of Nutrition, ICMR, Hyderabad, India. The ICMR recommends $600 \mathrm{mg}$ of calcium for ages 1-10 years and $800 \mathrm{mg}$ for ages $11-18$ years for both genders. ${ }^{34)}$ The mean dietary calcium intake in boys and girls was adequate as per the RDA recommended by ICMR (2010) (boys: $1151 \pm 451 \mathrm{mg} /$ daily; girls $1080 \pm 390 \mathrm{mg} /$ daily), but was significantly higher in boys than girls (median [range]: boys, $1,001 \mathrm{mg}(600-3,559 \mathrm{mg})$ and girls, $953 \mathrm{mg}$ [616-3477 mg]; $P=0.031$ [Mann-Whitney test]).

\section{Data collection}

Anthropometric measurements such as height, weight, and body mass index (BMI) were noted at baseline. Height was measured to the nearest $0.1 \mathrm{~cm}$ using a portable wall mounted stadiometer (Holten's Stadiometer, 200 cm/78 inches, Model

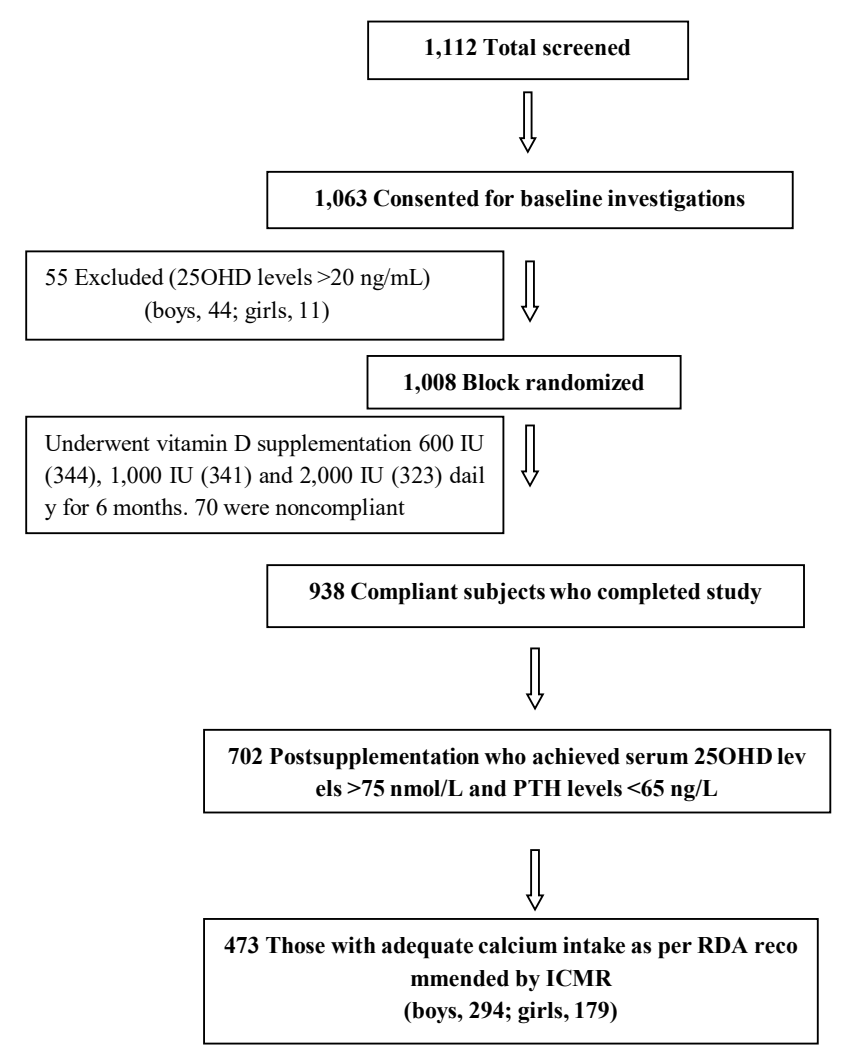

Fig. 1. Consortium flow diagram. 25OHD, 25-hydroxy-vitamin D; PTH, parathyroid hormone; RDA, recommended daily allowance; ICMR, Indian Council of Medical Research. 
WS045, Narang Medical Ltd., Delhi, India) with subjects standing straight with their head held in the Frankfurt plane. Weight was measured to the nearest $0.1 \mathrm{~kg}$ without shoes on and with light clothes on using an electronic scale (EQUINOX Digital weighing machine, Model EB6171, Equinox Overseas Private Ltd., New Delhi, India). BMI defined as the ratio of body weight to height squared and expressed in $\mathrm{kg} / \mathrm{m}^{2}$. Weight categories were defined by revised criteria of the Indian Association of Pediatrics. Participants above the adult equivalent BMI of $23 \mathrm{~kg} / \mathrm{m}^{2}$ were defined as overweight, and those above the adult equivalent BMI of $27 \mathrm{~kg} / \mathrm{m}^{2}$ were defined as obese. $^{35)}$

Blood samples were collected in the fasting state between 8:00 AM to 9:00 AM and centrifuged. The serum was separated into three aliquots at the study site and transported in dry ice to the laboratory. Serum calcium, phosphorus, and alkaline phosphatase (ALP) were estimated on the same day. The 2 remaining aliquots were frozen at $-20^{\circ} \mathrm{C}$ for estimation of serum 25OHD and PTH at a later date. Serum calcium, serum phosphate, and serum ALP were measured with a commercially available kit using an automated biochemistry analyzer Cobas-c 501 (Roche Diagnostics, Manhiem, Germany). The normal ranges were: for serum total calcium, $2.2-2.7 \mathrm{mmol} /$ $\mathrm{L}$ for 2-12 year old children and 2.1-2.6 mmol/L for $12-18$ year old children; inorganic phosphorus, $1.0-1.7 \mathrm{mmol} / \mathrm{L}$ for 7-12 year old children and $0.9-1.5 \mathrm{mmol} / \mathrm{L}$ for $13-16$ year old children; ALP, $129-417$ U/L for $10-<13$ year old children, 57-254 U/L for $13-<15$ year old children, 50-117 U/L for $15-<18$ year old girls, $129-417 \mathrm{U} / \mathrm{L}$ for $10-<13$ year old boys, $116-468 \mathrm{U} / \mathrm{L}$ for $13-<15$ year old boys, and $82-331 \mathrm{U} / \mathrm{L}$ for
$15-<18$ year old boys. Serum 25OHD was assayed using a chemiluminescence method (Diasorin, Stillwater, MN, USA), and PTH (reference range, $10-65 \mathrm{ng} / \mathrm{L}$ ) was assayed using an electrochemiluminiscence assay (Roche Diagnostics, GMDMManheim, Germany). Intra- and interassay coefficients of variation were $3.5 \%$ and $5 \%$, respectively, for serum $25 \mathrm{OHD}$ and $2.4 \%$ and $3.6 \%$, respectively, for serum PTH. Urinary samples were collected to assess random $\mathrm{UCaCrR}$ (both calcium and creatinine measured in $\mathrm{mg}$ ) using the Cobas-C 501 system (Roche Diagnostics).

\section{Statistical analysis}

Analysis was performed using IBM SPSS Statistics ver. 20.0 (IBM Co., Armonk, NY, USA). Descriptive statistics were calculated as the mean \pm standard deviation (95\% confidence intervals). Significance of the parameters between genders was calculated via the Student $t$-test, and analysis of variance was used to study the difference in means of various parameters among weight groups. Dietary calcium, serum PTH, urinary calcium, urinary creatinine, and UCaCrR were not normally distributed so were also expressed as medians and ranges. These parameters were analyzed with Mann-Whitney and Kruskal-Wallis tests. Pearson correlation was used to evaluate the relationship between various parameters and UCaCrR. A $P$-value of $<0.05$ was considered statistically significant.

\section{Results}

The baseline anthropometric, biochemical, and hormonal

Table 1. Baseline anthropometric, biochemical, and hormonal parameters of study subjects

\begin{tabular}{|c|c|c|c|}
\hline Parameter & Boys $(n=294)$ & Girls $(n=179)$ & $P$-value \\
\hline Age (yr) & $11.2 \pm 2.6$ & $11.2 \pm 2.6$ & 0.981 \\
\hline Height (m) & $1.45 \pm 0.15$ & $1.43 \pm 0.13$ & 0.108 \\
\hline Weight (kg) & $39.1 \pm 13.6$ & $37.3 \pm 12.4$ & 0.147 \\
\hline BMI $\left(\mathrm{kg} / \mathrm{m}^{2}\right)$ & $18.1 \pm 3.6$ & $17.8 \pm 3.6$ & 0.394 \\
\hline Dietary calcium (mg/day) $)^{*}$ & $1151 \pm 451$ & $1080 \pm 390$ & 0.031 \\
\hline Median (range) & $1,001(600-3,559)$ & $953(616-3,477)$ & \\
\hline Serum calcium (mmol/L) & $2.44 \pm 0.06$ & $2.44 \pm 0.07$ & 0.981 \\
\hline Serum phosphates (mmol/L) & $1.58 \pm 0.17$ & $1.54 \pm 0.21$ & 0.041 \\
\hline Serum ALP (U/L) & $274.4 \pm 84.3$ & $230.0 \pm 86.2$ & $<0.001$ \\
\hline Serum 25OHD (nmol/L) & $82.1 \pm 25.5$ & $86.4 \pm 31.7$ & 0.119 \\
\hline Serum PTH $(n g / L)^{*}$ & $32.5 \pm 12.1$ & $35.0 \pm 12.0$ & 0.033 \\
\hline Median (range) & $31.0(9.8-63.8)$ & $35.0(14.5-62.8)$ & \\
\hline Urinary calcium (mg/dL) ${ }^{*}$ & $6.1 \pm 6.7$ & $6.1 \pm 5.9$ & 0.972 \\
\hline Median (range) & $4.1(0.06-50.24)$ & $3.8(0.20-29.0)$ & \\
\hline Urinary creatinine $(\mathrm{mg} / \mathrm{dL})^{*}$ & $116.1 \pm 69.6$ & $119.1 \pm 74.6$ & 0.846 \\
\hline Median (range) & $101.6(10.6-316.0)$ & $101.0(7.2-388.5)$ & \\
\hline $\mathrm{UCaCrR}(\mathrm{mg} / \mathrm{mg})^{*}$ & $0.053 \pm 0.037$ & $0.053 \pm 0.037$ & 0.992 \\
\hline Median (range) & $0.047(0.001-0.212)$ & $0.044(0.001-0.152)$ & \\
\hline
\end{tabular}

Values are presented as the mean \pm standard deviation unless otherwise indicated.

BMI, body mass index; ALP, alkaline phosphatase; 25OHD, 25-hydroxy-vitamin D; PTH, parathyroid hormone; UCaCrR, urinary calcium creatinine ratio.

"Mann-Whitney test. 
parameters of participants are presented in Table 1 . The mean age and BMI of 473 study subjects ( $62.2 \%$ boys, $37.8 \%$ girls) were $11.2 \pm 2.6$ years and $18.0 \pm 3.6 \mathrm{~kg} / \mathrm{m}^{2}$, respectively. Most parameters in boys and girls presented in Table 1 were comparable except for dietary calcium intake, serum phosphate, ALP, and PTH. Forty subjects (8.5\%) were obese, 81 (17.1\%) were overweight, and the remaining 352 subjects were normal weight. The overall mean serum $25 \mathrm{OHD}$ and $\mathrm{PTH}$ were $33.6 \pm 11.2 \mathrm{ng} / \mathrm{mL}$ and $33.5 \pm 12.1 \mathrm{pg} / \mathrm{mL}$, respectively.

There was no gender difference observed in the mean and median values of random UCaCrR (Table 1). The mean values, percentiles (5th, 50th, 95th, and 97.5th), and 95\% confidence intervals of UCaCrR by age are given in Table 2. The UCaCrR was significantly higher in prepubertal subjects (age $\leq 10$ years) ( mean $=0.059 \pm 0.037$, median $=0.055,95$ th percentile $=0.136)$ compared to those $>10$ years old $($ mean $=0.050 \pm 0.036$, median $=$ $0.041,95$ th percentile $=0.123)(P=0.02)$. The maximum mean and median values of UCaCrR were observed at 8 years. The minimum median value of UCaCrR was at 14 years of age, and the minimum mean value was at 11 years of age. The 95th percentile of UCaCrR in the study population was 0.126 (Table 2). There was no difference in UCaCrR between different

Table 2. Mean values, reference ranges, and percentiles of urinary calcium creatinine ratio according to age group

\begin{tabular}{lllllccccc}
\hline Age $(\mathrm{yr})$ & No. & Mean & SD & Range & $95 \% \mathrm{Cl}$ & 5 th & 50 th & 95 th & 97.5 th \\
\hline $5-7^{*}$ & 21 & 0.0571 & 0.0344 & $0.008-0.137$ & $0.0414-0.0728$ & 0.009 & 0.0506 & 0.133 \\
8 & 38 & 0.0618 & 0.0404 & $0.002-0.142$ & $0.0485-0.0751$ & 0.005 & 0.0606 & 0.141 & 0.137 \\
9 & 48 & 0.0529 & 0.0373 & $0.007-0.178$ & $0.0421-0.0638$ & 0.007 & 0.0507 & 0.111 & 0.163 \\
10 & 50 & 0.0623 & 0.0379 & $0.006-0.143$ & $0.0518-0.0727$ & 0.008 & 0.0580 & 0.139 & 0.143 \\
11 & 56 & 0.0465 & 0.0304 & $0.002-0.131$ & $0.0384-0.0547$ & 0.008 & 0.0381 & 0.101 & 0.130 \\
12 & 79 & 0.0518 & 0.0362 & $0.002-0.147$ & $0.0435-0.0601$ & 0.007 & 0.0422 & 0.125 \\
13 & 71 & 0.0482 & 0.0349 & $0.002-0.182$ & $0.0399-0.0453$ & 0.009 & 0.0389 & 0.126 & 0.146 \\
14 & 43 & 0.0475 & 0.0372 & $0.002-0.185$ & $0.0361-0.0590$ & 0.009 & 0.0359 & 0.144 & 0.181 \\
15 & 25 & 0.0480 & 0.0363 & $0.003-0.115$ & $0.0330-0.0630$ & 0.008 & 0.0394 & 0.144 & 0.145 \\
16 & 21 & 0.0601 & 0.0498 & $0.012-0.212$ & $0.0374-0.0828$ & 0.013 & 0.0422 & 0.203 & 0.212 \\
$>16-18^{\dagger}$ & 21 & 0.0597 & 0.0360 & $0.004-0.135$ & $0.0433-0.0762$ & 0.005 & 0.0595 & 0.134 & 0.138 \\
Total & 473 & 0.0530 & 0.0368 & $0.002-0.212$ & $0.0497-0.0564$ & 0.008 & 0.0453 & 0.126 \\
\hline
\end{tabular}

SD, standard deviation; $\mathrm{Cl}$, confidence interval.

"Because of the small number of subjects (1) in age group 6, numbers are combined with age groups 5-7 years. ${ }^{\dagger}$ Because of the small number of subjects (6) in age group 17-18 years, numbers are combined with age group 16-18 years.

Table 3. Comparative description of anthropometry, biochemistry, hormonal status, and urinary calcium creatinine ratio according to weight category

\begin{tabular}{|c|c|c|c|c|}
\hline Parameter & Normal $(n=352)$ & Overweight $(n=81)$ & Obese $(n=40)$ & $P$ for trend \\
\hline Age (yr) & $11.2 \pm 2.5$ & $11.4 \pm 3.0$ & $10.9 \pm 2.3$ & 0.602 \\
\hline Height (m) & $1.43 \pm 0.14$ & $1.46 \pm 0.15$ & $1.47 \pm 0.15$ & 0.271 \\
\hline Weight (kg) & $34.9 \pm 10.4$ & $45.7 \pm 13.5$ & $54.3 \pm 16.8$ & $<0.001$ \\
\hline $\mathrm{BMI}\left(\mathrm{kg} / \mathrm{m}^{2}\right)$ & $16.6 \pm 2.3$ & $21.0 \pm 2.4$ & $24.5 \pm 3.8$ & $<0.001$ \\
\hline Dietary calcium (mg) & $1132 \pm 432$ & $1071 \pm 350$ & $1160 \pm 540$ & 0.430 \\
\hline Median (range) & $994(613-3,546)$ & $899(600-2,395)$ & $968(651-3,559)$ & \\
\hline Serum calcium (mmol/L) & $2.43 \pm 0.07$ & $2.45 \pm 0.07$ & $2.45 \pm 0.07$ & 0.357 \\
\hline Serum phosphates $(\mathrm{mmol} / \mathrm{L})$ & $1.58 \pm 0.19$ & $1.55 \pm 0.19$ & $1.55 \pm 0.19$ & 0.445 \\
\hline Serum ALP (U/L) & $259.7 \pm 88.1$ & $245.0 \pm 83.7$ & $264.8 \pm 91.3$ & 0.341 \\
\hline Serum 25OHD (nmol/L) & $84.9 \pm 29.0$ & $82.6 \pm 27.2$ & $77.4 \pm 27.2$ & 0.264 \\
\hline Serim PTH (ng/L) & $33.3 \pm 12.1$ & $34.1 \pm 11.7$ & $33.4 \pm 12.6$ & 0.885 \\
\hline Median (range) & $31.9(9.8-63.7)$ & $32.6(10.8-62.8)$ & $32.1(12.3-63.8)$ & \\
\hline Urinary calcium (mg/dL) & $6.1 \pm 6.7$ & $5.1 \pm 4.8$ & $7.9 \pm 6.4$ & 0.040 \\
\hline Median (range) & $3.9(0.06-50.24)$ & $3.6(0.28-19.8)$ & $6.5(0.37-25.3)$ & \\
\hline Urinary creatinine $(\mathrm{mg} / \mathrm{dL})^{*}$ & $116.4 \pm 70.4$ & $112.2 \pm 74.5$ & $134.7 \pm 73.4$ & 0.178 \\
\hline Median (range) & $101.5(10.6-388.5)$ & $93.1(7.1-315.9)$ & $122.1(18.1-288.2)$ & \\
\hline $\operatorname{UCaCrR}(\mathrm{mg} / \mathrm{mg})^{*}$ & $0.0529 \pm 0.037$ & $0.0510 \pm 0.035$ & $0.0488 \pm 0.035$ & 0.353 \\
\hline Median (range) & $0.0434(0.002-0.212)$ & $0.0444(0.002-0.144)$ & $0.0535(0.002-0.142)$ & \\
\hline
\end{tabular}

Values are presented as the mean \pm standard deviation unless otherwise indicated.

BMI, body mass index; ALP, alkaline phosphatase; 25OHD, 25-hydroxy-vitamin D; PTH, parathyroid hormone; UCaCrR, urinary calcium creatinine ratio.

"Mann-Whitney test. 

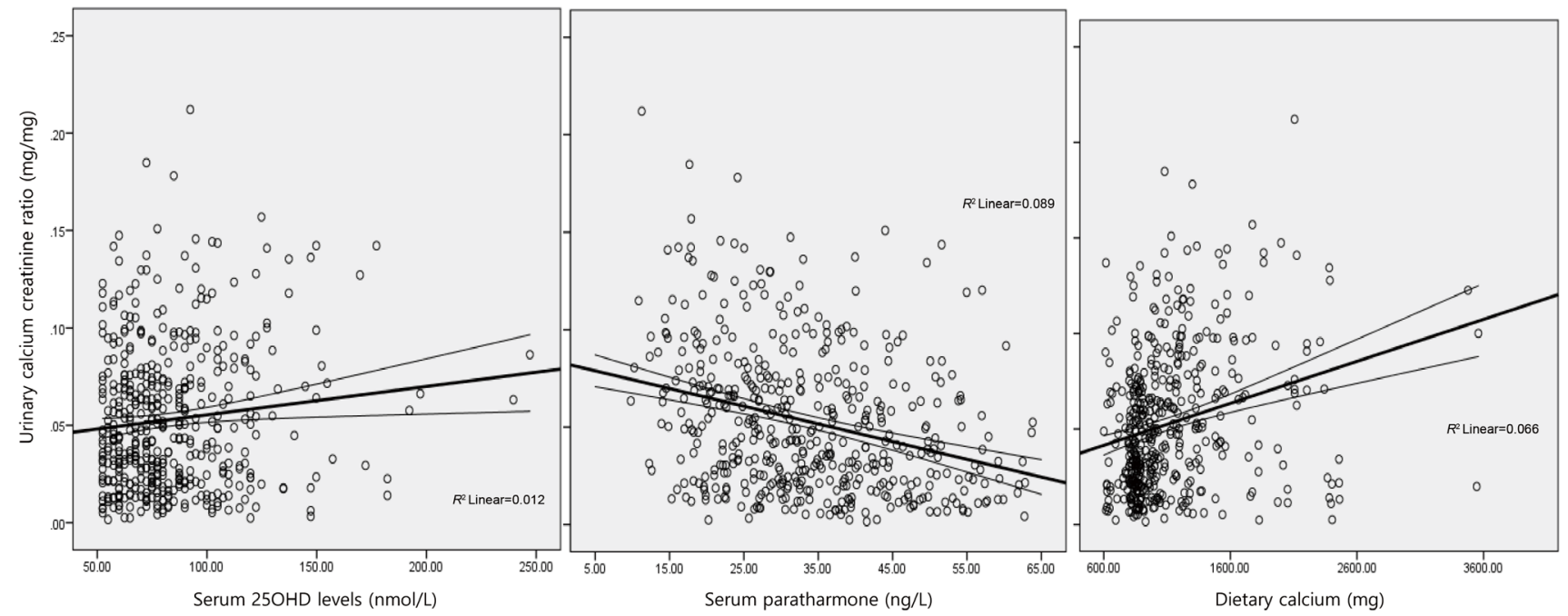

Fig. 2. Scatter plot showing correlation between urinary calcium creatinine ratio and serum 25-hydroxy-vitamin D (25OHD) (A), parathyroid hormone (B), and dietary calcium (C). Lines denote a linear correlation with mean confidence interval.

weight categories $(P=0.353)$ (Table 3$)$.

UCaCrR was positively correlated with dietary calcium intake $(r=0.256, P<0.001)$ (Fig. 2$)$ and serum 25OHD $(r=0.111$, $P=0.016$ ) (Fig. 2), and it was inversely correlated with serum PTH $(r=-0.299, P<0.001)$ (Fig. 2$)$ and serum ALP $(r=-0.098$, $P=0.037)$. There was no significant correlation between $\mathrm{UCaCrR}$ and age $(r=-0.040, P=0.382)$, BMI $(r=0.019, P=0.331)$, or serum calcium $(r=0.078, P=0.089)$.

\section{Discussion}

$\mathrm{UCaCrR}$ is used to monitor calcium and vitamin D supplementation and various other diseases. ${ }^{1,2)}$ Although 24-hour urinary calcium excretion is considered the gold standard, ${ }^{11)}$ there are practical difficulties in collecting 24-hour urinary samples, particularly in the pediatric population. ${ }^{12)}$ Collection of spot or random urine samples, an easy and practical method to assess calcium excretion, has been recommended for epidemiologic studies. ${ }^{12-14)}$ Since there is wide variation in $\mathrm{UCaCrR}$ values among various geographic regions, reference ranges and 95th percentile values specific for each population are needed. ${ }^{4-10,14-27)}$ In the present study, we report normative data of UCaCrR in healthy North Indian children and adolescents.

The overall mean UCaCrR of $0.0530 \pm 0.0368$ was significantly lower than values reported from different geographic regions such as Turkey, Lebanon, Iran, Italy, and Argentina, ${ }^{5,8,10,13,23,24,27,36)}$ including a report from India where the reported mean was $0.10 \pm 0.094{ }^{29)}$ The 95 th percentile of $\mathrm{UCaCrR}$ in the present study was 0.14 and ranged from $0.10-0.20$ among different age groups. Cutoff values of $<0.20^{1)}$ and $<0.21^{3)}$ have been considered normal in studies including children older than 2 years. Two earlier studies from India reported varied cutoff values of $0.15^{30)}$ and $0.29{ }^{29)}$ Cutoff values used to define hypercalciuria in children vary widely by country and range from the lowest value of 0.15 in India ${ }^{28}$ to the highest value of 0.36 in Iran. ${ }^{36)}$ Cutoff values from most other countries ranged from $0.20-0.29^{4-10,12,13,20)}$ The present study reports lower UCaCrR cut off levels than most other published studies, except one from Korea.

The lower $\mathrm{UCaCrR}$ value in the present study emphasizes that daily dietary calcium intake and vitamin D status are important determinants of UCaCrR. Variations in UCaCrR values in different populations are probably due to differences in daily dietary calcium intake ${ }^{37)}$ and serum levels of $25 \mathrm{OHD}^{38)}$ Mean serum 25OHD levels reach normal values of $>20 \mathrm{ng} / \mathrm{mL}$ and PTH returns to within normal range following 3 months of daily vitamin $D$ supplementation with, as shown in our previous study in school girls. ${ }^{30)}$ It is therefore safe to assume that children in the present study would have had normal bone turnover for at least 3 months with normal daily calcium intake. Hence, the $\mathrm{UCaCrR}$ in the present study with adequate intake of dietary calcium, normal serum 25OHD, and serum PTH within normal range for a sufficiently long duration of time (at least 3 months) reflects the true normative range of $\mathrm{UCaCrR}$ in Indian children.

Calcium excretion has also been correlated with salt intake and natriuresis. ${ }^{12)}$ A study from West Bengal, India, where the population consumes a high quantity of sea food with high salt content, reported high mean values of $\mathrm{UCaCrR}$ among children. ${ }^{39)}$

There are conflicting reports on the correlation of $\mathrm{UCaCrR}$ with age. Some studies have observed a strong correlation, ${ }^{7,9,36)}$ whereas others have shown either weak ${ }^{5,27)}$ or no correlation. ${ }^{24,29)}$ This likely results from the inclusion of different age ranges in different studies. Gül et al. ${ }^{20)}$ studied subjects with a similar age range in Turkey and also reported different values of UCaCrR among different age groups. We observed a sharp decline in $\mathrm{UCaCrR}$ at the age of 11 years, which was also noted in 
11-year-old children from Turkey ${ }^{20)}$ and 10-year-old Lebanese children. ${ }^{10)}$ This decline may be due to decreased dietary calcium intake with aging. The maximum UCaCrR noted at the age of 8 years in this study was consistent with similarly aged Iranian children. ${ }^{18)}$

A significantly higher mean $\mathrm{UCaCrR}$ in prepubertal children than peri-pubertal and pubertal children was also reported among children from Turkey ${ }^{20)}$ and Iran. ${ }^{23)}$ These differences are explained by the following observations: (1) significantly higher serum $25 \mathrm{OHD}$ levels in prepubertal children compared to periand postpubertal children $(88.5 \pm 33.5 \mathrm{nmol} / \mathrm{L}$ vs. $81.6 \pm 24.5$ $\mathrm{nmol} / \mathrm{L}, P=0.011$ ) has also been reported ${ }^{8,9}$; (2) a positive correlation between UCaCrR and calcium intake has been reported with higher daily intake of calcium per kg body weight in children $\leq 10$ years compared to those $>10$ years $(40.4 \pm 18.6$ vs. $28.4 \pm 13.3, P<0.001)^{40)}$; (3) lower urinary creatinine values in children $\leq 10$ years compared to those $>10$ years $(100 \pm 71 \mathrm{mg}$ vs. $126 \pm 70 \mathrm{mg}, P<0.001)$ may also reflect lower UCaCrR; and (4) although sodium intake also affects calcium excretion, ${ }^{39)}$ it was not assessed in this study.

The absence of a difference in UCaCrR among genders in the present study was also observed in several other studies, including one from India. ${ }^{5,10,13,29,39)}$ However, Nuzzo et al. ${ }^{24)}$ from Italy and Wong et al. ${ }^{26}$ from China reported significantly higher $\mathrm{UCaCrR}$ values in girls. The lack of correlation between $\mathrm{UCaCrR}$ and weight categories seen in the present study was also reported by Gül et al. ${ }^{20)}$ and Nuzzo et al. ${ }^{24)}$

Natriuresis is associated with calciuresis. ${ }^{12)}$ Hence, sodium intake is likely to affect UCaCrR. In this study, we did not assess dietary intake of salt or measured urinary sodium, which is a limitation of our study.

In conclusion, the cutoff value of UCaCrR used to define hypercalciuria in vitamin D sufficient North Indian children with adequate daily intake of calcium and without secondary hyperparathyroidism is 0.13 for children and adolescents $>10$ years and 0.14 for children between $5-10$ years. No significant difference in UCaCrR was noted between genders and among different weight categories. Reported differences in UCaCrR values in different populations and age groups are likely due to differences in daily dietary calcium intake and serum 25OHD levels.

\section{Ethical statement}

This study protocol was approved by the Institute Ethical committee of All India Institute of Medical Sciences, New Delhi. This study was performed with consent from school authorities, parents/guardians, and verbal assent from children. Parents were asked to sign the consent form after they were provided with details of the study in a patient information sheet and allowed to ask the first author any questions.

\section{Conflict of interest}

No potential conflict of interest relevant to this article was reported.

\section{Acknowledgments}

Nestle R\&D, India Pvt Ltd has provided funds for the study. The funding organisation played no role in the study design; in the collection of data; in the writing of the report; or in the decision to submit the report for publication.

We thank the principals, parents and children for participating in this trial.

\section{References}

1. Leslie SW, Taneja A. Hypercalciuria. Stat Pearls [Internet]. Treasure Island (FL): Stat Pearls Publishing, 2017 Dec 14 [updated 2018 Dec 6]. Available from: https://www.ncbi. nlm.nih.gov/books/NBK448183/.

2. Miyai K, Onishi T, Kashimada K, Hasegawa Y. Urinary calcium to creatinine ratio: a potential marker of secondary hyperparathyroidism in patients with vitamin $\mathrm{D}$-dependent rickets type 1A. Endocr J 2015;62:61-8.

3. Metz MP. Determining urinary calcium/creatinine cut-offs for the paediatric population using published data. Ann Clin Biochem 2006;43(Pt 5):398-401.

4. Ring E, Borkenstein M. Use of the calcium-creatinine ratio in diagnosis and therapy. Padiatr Padol 1987;22:245-50.

5. Sönmez F, Akçanal B, Altincik A, Yenisey C. Urinary calcium excretion in healthy Turkish children. Int Urol Nephrol 2007;39:917-22.

6. Vachvanichsanong P, Lebel L, Moore ES. Urinary calcium excretion in healthy Thai children. Pediatr Nephrol 2000;14:847-50.

7. So NP, Osorio AV, Simon SD, Alon US. Normal urinary calcium/creatinine ratios in African-American and Caucasian children. Pediatr Nephrol 2001;16:133-9.

8. Ceran O, Akin M, Aktürk Z, Ozkozaci T. Normal urinary calcium/creatinine ratios in Turkish children. Indian Pediatr 2003;40:884-7.

9. Sargent JD, Stukel TA, Kresel J, Klein RZ. Normal values for random urinary calcium to creatinine ratios in infancy. J Pediatr 1993;123:393-7.

10. El Mallah C, Ghattas H, Shatila D, Francis S, Merhi K, Hlais $\mathrm{S}$, et al. Urinary magnesium, calcium, and phosphorus to creatinine ratios of healthy elementary school lebanese children. Biol Trace Elem Res 2016;170:264-70.

11. Esteghamati M, Ghasemi K, Nami M. Prevalence of idiopathic hypercalciuria in children with urinary system related symptoms attending a pediatric hospital in Bandar Abbas in 2014. Electron Physician 2017;9:5261-64.

12. Penido MG, Diniz IS, Guimarães MM, Cardoso RB, Souto MF, Penido MG. Urinary excretion of calcium, uric acid 
and citrate in healthy children and adolescents. J Pediatr (Rio J) 2002;78:153-60.

13. Emamghorashi F, Davami MH, Rohi R. Hypercalciuria in Jahrom's school-age children: what is normal calciumcreatinine ratio? Iran J Kidney Dis 2010;4:112-5.

14. Lavocat MP, Freycon MT, Muchrif M. Comparative study of 24-hour calciuria and urinary calcium/creatinine ratio in children over 4 years of age. Pediatrie 1992;47:565-8.

15. Reusz GS, Dobos M, Byrd D, Sallay P, Miltényi M, Tulassay T. Urinary calcium and oxalate excretion in children. Pediatr Nephrol 1995;9:39-44.

16. Alconcher LF, Castro C, Quintana D, Abt N, Moran L, Gonzalez L, et al. Urinary calcium excretion in healthy school children. Pediatr Nephrol 1997;11:186-8.

17. Mir S, Serdaroglu E. Quantification of hypercalciuria with the urine calcium osmolality ratio in children. Pediatr Nephrol 2005;20:1562-5.

18. Koyun M, Güven AG, Filiz S, Akman S, Akbas H, Baysal YE, et al. Screening for hypercalciuria in schoolchildren: what should be the criteria for diagnosis? Pediatr Nephrol 2007;22:1297-301.

19. Carrasco R, Lovell DJ, Giannini EH, Henderson CJ, Huang B, Kramer S, et al. Biochemical markers of bone turnover associated with calcium supplementation in children with juvenile rheumatoid arthritis: results of a double-blind, placebo-controlled intervention trial. Arthritis Rheum 2008;58:3932-40.

20. Gül A, Özer S, Yılmaz R, Sönmezgöz E, Kasap T, Takçı Ş, et al. Prevalence of hypercalciuria and urinary calcium excretion in school-aged children in the province of Tokat. Turk Pediatri Ars 2016;51:193-7.

21. Touitou Y, Auzéby A, Camus F, Djeridane Y. Twenty-fourhour profiles of urinary excretion of calcium, magnesium, phosphorus, urea, and creatinine in healthy prepubertal boys. Clin Biochem 2010;43:102-5.

22. Hilgenfeld MS, Simon S, Blowey D, Richmond W, Alon US. Lack of seasonal variations in urinary calcium/creatinine ratio in school-age children. Pediatr Nephrol 2004;19:11535.

23. Safarinejad MR. Urinary mineral excretion in healthy Iranian children. Pediatr Nephrol 2003;18:140-4.

24. Nuzzo V, Fittipaldi MR, Fonderico F, Esposito Del Puente A, Russo D, Del Puente A, et al. Urinary calcium excretion in a population of children living in Southern Italy. Minerva Pediatr 1999;51:53-6.

25. Selimoğlu MA, Alp H, Bitlisli H, Orbak Z, Energin M, Karakelleoğlu C. et al. Urinary calcium excretion of children living in the east region of Turkey. Turk J Pediatr 1998;40:399-404.

26. Wong GW, Lam CW, Kwok MY, Mak TW. Urinary calcium excretion in Chinese adolescents. J Paediatr Child Health 1998;34:226-8.

27. Esbjörner E, Jones IL. Urinary calcium excretion in Swedish children. Acta Paediatr 1995;84:156-9.
28. Sweid HA, Bagga A, Vaswani M, Vasudev V, Ahuja RK, Srivastava RN. Urinary excretion of minerals, oxalate, and uric acid in north Indian children. Pediatr Nephrol 1997;11:189-92.

29. Rath B, Aggarwal MK, Mishra TK, Talukdar B, Murthy NS, Kabi BC. Urinary calcium creatinine ratio and hypercalciuria. Indian Pediatr 1994;31:311-6.

30. Khadgawat R, Marwaha RK, Garg MK, Ramot R, Oberoi AK, Sreenivas V, et al. Impact of vitamin D fortified milk supplementation on vitamin D status of healthy school children aged 10-14 years. Osteoporos Int 2013;24:2335-43.

31. Marwaha RK, Garg MK, Sethuraman G, Gupta N, Mithal A, Dang N et al. Impact of three different daily doses of vitamin D3 supplementation in healthy school children and adolescents from North India: A single- blind prospective randomized clinical trial. Br J Nutr 2019;121:538-548.

32. Sacheck JM, Van Rompay MI, Chomitz VR, Economos CD, Eliasziw M, Goodman E, et al. Impact of Three Doses of Vitamin D3 on Serum 25(OH)D Deficiency and Insufficiency in At-Risk Schoolchildren. J Clin Endocrinol Metab 2017;102:4496-4505.

33. Al-Shaar L, Mneimneh R, Nabulsi, Maalouf J, Fuleihan Gel-H. Vitamin D3 dose requirement to raise 25-hydroxyvitamin $\mathrm{D}$ to desirable levels in adolescents: results from a randomized controlled trial. J Bone Miner Res 2014;29:944-51.

34. Narasinga Rao BS, Sivakumar B. Nutritional requirements and recommended daily allowances for Indians. A report of expert group of Indian Council of Medical Research. 2nd ed. New Delhi (India): National Institute of Nutrition, 2010.

35. Indian Academy of Pediatrics Growth Charts Committee, Khadilkar V, Yadav S, Agrawal KK, Tamboli S, Banerjee M, et al. Revised IAP growth charts for height, weight and body mass index for 5- to 18-year-old Indian children. Indian Pediatr 2015;52:47-55.

36. Sorkhi H, Haji Aahmadi M. Urinary calcium to creatinin ratio in children. Indian J Pediatr 2005;72:1055-6.

37. Balk EM, Adam GP, Langberg VN, Earley A, Clark P, Ebeling PR, et al. Global dietary calcium intake among adults: a systematic review. Osteoporos Int 2017;28:331524.

38. Wahl DA, Cooper C, Ebeling PR, Eggersdorfer M, Hilger J, Hoffmann K, et al. A global representation of vitamin D status in healthy populations. Arch Osteoporos 2012;7:15572.

39. Pal M, Datta S, Pradhan AK, Ghosh T, Ganguly A, Basu S, et al. Determination of upper reference value of urinary calcium-creatinine ratio for the pediatric population in Burdwan district. Adv Biol Chem 2013;3:455-9.

40. Ekbote VH, Khadilkar AV, Khadilkar VV, Chiplonkar SA, Mughal Z. Dietary patterns with special reference to calcium intake in 2-16-year-old Urban Western Indian children. Indian J Public Health 2017;61:188-93. 